\title{
The Effect of Transformation to the Amorphous Structure on the Corrosion Resistance of Palladium Alloy Anodes for the Electrolysis of Hot Concentrated $\mathrm{NaCl}$ Solution
}

\author{
Motoi Hara*†, Katsuhiko Asami*, Koji Hashimoto* \\ and Tsuyoshi Masumoto* \\ *The Research Institute for Iron, Steel and Other Metals, Tohoku University
}

\begin{abstract}
The origin of high corrosion resistance of amorphous palladium-phosphorus alloys containing iridium or rhodium during anodic polarization for chlorine evolution in a hot concentrated $\mathrm{NaCl}$ solution was investigated by comparing with the corresponding crystalline alloys. The amorphous alloys steadily evolved chlorine gas without dissolution, whereas the crystalline alloys consisting multiple phases suffered vigorous dissolution because of selective attack of palladiumrich phases. Furthermore, the corrosion resistance of amorphous alloys is higher than that of crystalline single phase alloys, since the concentration of passivating species such as iridium or rhodium ion in the surface film formed on the amorphous alloys during the electrolysis was higher than that on the crystalline alloys, as well as the crystalline defect-free structure of the amorphous alloys.
\end{abstract}

\section{Introduction}

Palladium metal has excellent characteristics as an anode for the electrolysis of sodium chloride solutions: the high catalytic activity for chlorine evolution and high overvoltage for competing oxygen evolution $^{1)}$. However, palladium metal is not practically used as an anode for the electrolytic soda process because of its low corrosion resistance.

On the other hand, it has been known that certain amorphous alloys prepared by rapid quenching from the liquid state have extremely high corrosion resistance even in acidic chloride environments $^{2) \sim 8)}$. The present authers ${ }^{\text {7) }}{ }^{10}$ ) have prepared various palladium-base amorphous alloys and examined thier anodic characteristics in a hot concentrated sodium chloride solution with a view to improving the corrosion resistance of palladium without harming its superior electrode characteristics for the electrolysis of sodium

* Katahira, Sendai 980, Japan

+ Present address: Department of Metallurgy, Mining College, Akita University, Akita 010, Japan chloride solution. The amorphous ternary palladium-phosphorus alloys containing sufficient amounts of rhodium, platinum or iridium possess a high corrosion resistance under evolution of chlorine $^{9)}$. They have the low activity for oxygen evolution, and among them the amorphous PdIr-P alloys show the higher electrocatalytic activity for chlorine evolution ${ }^{10}$.

The present work has been undertaken to clarify the origin of the high corrosion resistance of amorphous palladium alloy electrodes used for chlorine evolution in a hot concentrated sodium chloride solution, their anodic characteristics being compared with the corresponding crystalline alloys.

\section{Experimental Procedures}

\subsection{Preparation of alloys}

Crystalline alloy casts were prepared as follows: After prescribed amounts of $99.9 \%$ pure palladium chips and reagent grade red phosphorus were vacuum-sealed in a quartz ampoule so as 
to put palladium chips on red phosphorus, the reaction of palladium with phosphorus vapor was carried out at $400^{\circ} \mathrm{C}$ for 2 days and then the temperature was gradually raised to melt palladium phosphide for homogenization. After palladium phosphide thus prepared was melted with various amounts of $99.9 \%$ pure iridium or rhodium powder under an argon atmosphere, the alloy casts were prepared by sucking up the melt into a quartz tube and subsequent water-quenching. After the alloy cast was remelted in a quartz tube under an argon atmosphere, a jet of the molten alloy was impinged by pressurized argon gas onto the outer surface of a rapidly rotating wheel. By this method, the amorphous Pd-Ir-P and PdRh-P alloy ribbons of $1.0-1.5 \mathrm{~mm}$ width and 10-30 $\mu \mathrm{m}$ thickness were prepared. Crystalline Pd-Ir-P and Pd-Rh-P alloy casts were also used for comparison. In addition, crystalline $\mathrm{Pd}-\mathrm{Rh}$ alloy sheets of about $0.1-0.5 \mathrm{~mm}$ thickness were also prepared by argon-arc melting and subsequent rolling. Crystalline brittle Pd-Ir alloy sheets were also prepared as follows: After alloy casts prepared by argon-arc melting were sandwiched with type 304 steel sheets, they were hotforged at $1000^{\circ} \mathrm{C}$ and then cut into about $1 \mathrm{~mm}$ thickness. Finally both alloy sheets were recrystallized at about $1000^{\circ} \mathrm{C}$ for 1 day. Prior to electrochemical measurements, the amorphous alloy ribbons and crystalline alloy sheets were cut into about $15 \mathrm{~mm}$ in length and polished with emery paper to No. 2000, degreased ultrasonically with acetone and finally dried in air.

\subsection{Anodic polarization measurements}

Potentiostatic polarization curves were measured after polarization for $120 \mathrm{~s}$ at each potential which was changed by step-wise increase with a $0.05 \mathrm{~V}$ interval. $4 \mathrm{M} \mathrm{NaCl}$ solution of $\mathrm{pH} 4$ was used as an electrolyte. The $\mathrm{pH}$ of the solution was adjusted by adding $4 \mathrm{M} \mathrm{HCl}$. These solutions were prepared by using reagent grade chemicals and de-ionized water. During measurements, the electrolyte was open to air and kept at $80^{\circ} \mathrm{C}$.
An H-type electrolytic cell was used, in which anode and cathode compartments were separated by an asbestos diaphragm. The solution filled in each compartment was about $150 \mathrm{~m} l$. A platinum gauze and a saturated calomel electrode were used as counter and reference electrodes, respectively.

\subsection{Corrosion rate measurement}

(1) Measurement of weight loss

Alloy specimens spot-welded with a titanium wire of $0.1 \mathrm{~mm}$ diameter and $25 \mathrm{~mm}$ length were used for the wieght loss test. When an insulator coating was applied to expose a fixed area of the specimen to the solution, a prolonged polarization led to an erroneous result due to degradation of the coating by aggressive chlorine. Accordingly, a certain area of the specimen was directly immersed into the solution without a coating. The corrosion rate was estimated from the weight loss after potentiostatic polarization at $1.25 \mathrm{~V}$ (SCE). The weight of specimens was measured by a microbalance. The electrolyte and electrolytic cell used were the same as those for the anodic polarization measurement.

(2) Chemical analysis of dissolved species

Since the crystalline Pd-Ir-P and Pd-Ir alloys showed vigorous dissolution during potentiostatic polarization at $1.25 \mathrm{~V}$ (SCE), the chemical analysis of dissolved elements in the solution was carried out, and the total weights of elements analysed were assumed as the weight loss of the specimen.

\subsection{Measurement of X-ray photoelectron spectra}

$\mathrm{X}$-ray photoelectron spectra of the specimens were measured with AEI ES 200 electron spectrometer with $\mathrm{Mg} \mathrm{K}_{\alpha_{1,2}}$ excitation at a constant temperature of $50^{\circ} \mathrm{C}$. Integrated intensities of spectra were used to determine the composition and thickness of the surface film on the specimen. The method for quantitative determination ${ }^{11), 12)}$ and photoionization cross-sections ${ }^{13}$ ) used for the analysis were reported previously.

\subsection{Surface observation}

The surface of specimens polarized at gas evolution potentials were observed by JSM-U3 
scanning electron microscope. The intensities of characteristic X-rays for each element constituting the alloy surface were measured by SDS X-ray spectrometer attached to the JSM-U3.

\section{Results}

(a) Palladium-Iridium Alloys

\subsection{Anodic Polarization Behavior}

Figure 1 shows a potentiostatic anodic polarization curve of amorphous $\mathrm{Pd}_{41} \mathrm{Ir}_{40} \mathbf{P}_{19}$ alloy measured in $4 \mathrm{M} \mathrm{NaCl}$ solution of $\mathrm{pH} 4$ and $80^{\circ} \mathrm{C}$.

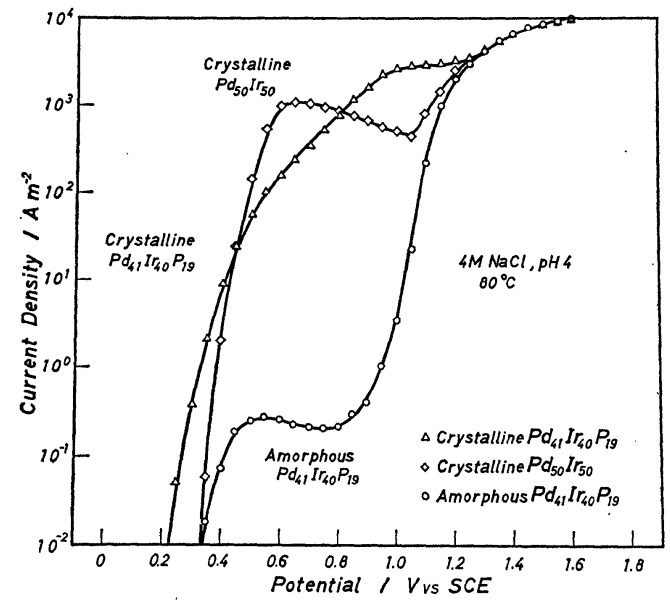

Fig. 1 Potentiostatic anodic polarization curves of amorphous $\mathbf{P d}_{41} \mathrm{Ir}_{40} \mathbf{P}_{19}$ alloy and crystalline $\mathbf{P d}_{41} \mathrm{Ir}_{40} \mathrm{P}_{19}$ and $\mathrm{Pd}_{50} \mathrm{Ir}_{50}$ alloys measured in $4 \mathrm{M} \mathrm{NaCl}$ of $\mathrm{pH} 4$ and $80^{\circ} \mathrm{C}$.

The figure includes anodic polarization curves of crystalline $\operatorname{Pd}_{41} \mathrm{Ir}_{40} \mathrm{P}_{18}$ and $\mathbf{P d}_{50} \mathrm{Ir}_{50}$ alloys for comparison. The amorphous alloy is passivated by anodic polarization and subsequently shows a steep increase in the current density corresponding to chlorine evolution at potentials higher than about $0.9 \mathrm{~V}$ (SCE). In contrast, the crystalline $\mathbf{P d}_{41} \operatorname{Ir}_{40} \mathbf{P}_{18}$ alloy dissolves actively without gas evolution at high potentials such as $1.15 \mathrm{~V}$ (SCE), the solution in the vicinity of the crystalline alloy being turned to brown color due to dissolution of the alloy. However, chlorine evolution is observed along with alloy dissolution in the potential region higher than $1.20 \mathrm{~V}$ (SCE). The crystalline $\mathrm{Pd}_{50} \mathrm{Ir}_{50}$ alloy tends to passivate with an increase in potential after active dissolution, and both vigorous dissolution and chlorine evolution are simultaneously observed at about 1.1 V (SCE). Further increase in polarization potential leads to a decrease in the dissolution rate and to an increase in the chlorine evolution rate.

In order to investigate the effect of difference between the crystalline and amorphous structures on the chlorine evolution and corrosion rates, the potentiostatic polarization of amorphous and crystalline alloys was carried out at $1.25 \mathrm{~V}$ (SCE) in $4 \mathrm{M} \mathrm{NaCl}$ solution of $\mathrm{pH} 4$ and $80^{\circ} \mathrm{C}$. The total weights of dissolved species during polarization were estimated by both the weight loss measurement and chemical analysis of dissolved
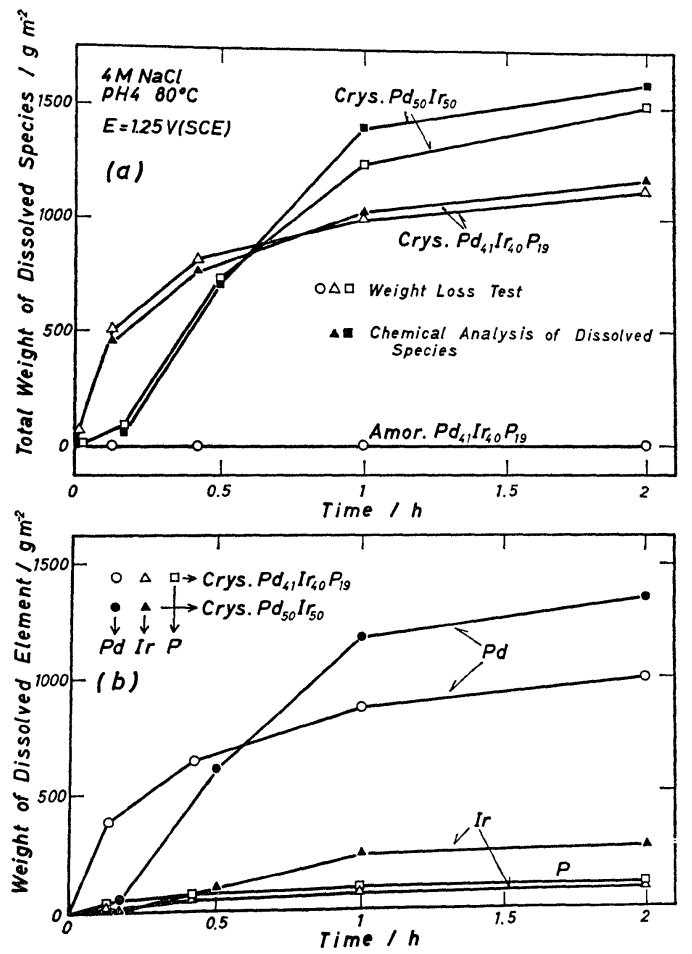

Fig. 2 (a) Changes in total weights of dissolved species from the crystalline $\mathrm{Pd}_{41} \mathrm{Ir}_{40} \mathrm{P}_{19}$ and $\mathrm{Pd}_{50} \mathrm{Ir}_{50}$ alloys during potentiostatic polarization at $1.25 \mathrm{~V}$ (SCE) in $4 \mathrm{M} \mathrm{NaCl}$ of $\mathrm{pH} 4$ and $80^{\circ} \mathrm{C}$. The weight change of the amorphous $\mathrm{Pd}_{41} \mathrm{Ir}_{40} \mathrm{P}_{19}$ was not detected.

(b) Changes in weights of dissolved elements from the crystalline $\operatorname{Pd}_{41} \operatorname{Ir}_{40} \mathrm{P}_{19}$ and $\mathrm{Pd}_{50} \mathrm{Ir}_{50}$ alloys during potentiostatic polarization at $1.25 \mathrm{~V}$ (SCE) in $4 \mathrm{M} \mathrm{NaCl}$ of $\mathrm{pH} 4$ and $80^{\circ} \mathrm{C}$. 
species. The results are shown in Fig. 2(a) as a function of time of polarization. The weight loss is in good agreement with the result of chemical analysis. The amounts dissolved from the crystalline $\mathbf{P d}_{41} \mathbf{I r}_{40} \mathbf{P}_{19}$ and $\mathbf{P d}_{50} \mathbf{I r}_{50}$ alloys increase asymptotically with time, while the amorphous alloy shows no detectable weight loss. Fig. 2(b) shows the change in the weights of dissolved elements with time. It is clear that palladium preferentially dissolves from the crystalline alloys.

The amount of charge consumed for dissolution during polarization was estimated from the weights of dissolved elements on the assumption that palladium, iridium and phosphorus dissolved as di-, tri- and penta-valent cations, respectively. The amount of charge for dissolution was converted to the average dissolution current density. The gas evolution current density was estimated as the difference between the current density

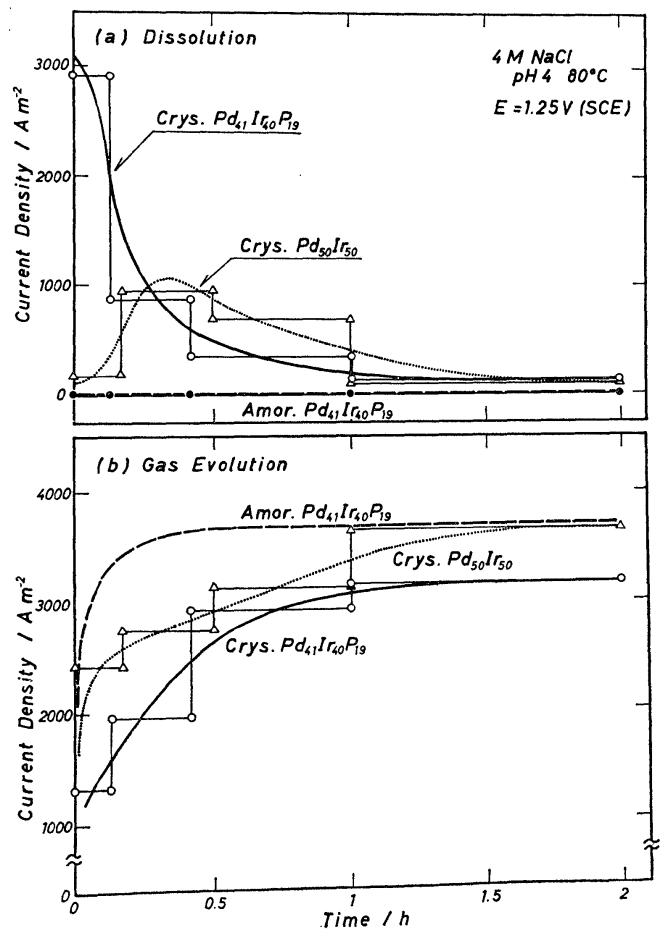

Fig. 3 Changes in current densities consumed for dissolution and gas evolution measured for amorphous $\mathrm{Pd}_{41} \mathrm{Ir}_{40} \mathrm{P}_{19}$ alloy and crystalline $\mathbf{P d}_{41} \operatorname{Ir}_{40} \mathbf{P}_{19}$ and $\mathbf{P d}_{50} \mathrm{Ir}_{50}$ alloys during potentiostatic polarization at $1.25 \mathrm{~V}$ (SCE) in $4 \mathrm{M} \mathrm{NaCl}$ of $\mathrm{pH} 4$ and $80^{\circ} \mathrm{C}$. observed and that for dissolution. The results are given in Fig. 3. Since the weight loss was not detected from the amorphous alloy, the current density observed from the amorphous alloy during potentiostatic polarization at $1.25 \mathrm{~V}$ (SCE) is shown in Fig. 3(b). The dissolution rates of the crystalline alloys are significantly high particularly for initial $1 \mathrm{~h}$ and they become brittle after polarization for $2 \mathrm{~h}$.

\subsection{Surface Observation and Analysis of the Surface Film Composition}

Fig. 4 shows the scanning electron micrographs of the surface of amorphous $\operatorname{Pd}_{41} \operatorname{Ir}_{40} \mathrm{P}_{19}$ alloy and crystalline $\mathrm{Pd}_{41} \mathrm{Ir}_{40} \mathrm{P}_{10}$ and $\mathrm{Pd}_{50} \mathrm{Ir}_{50}$ alloys polarized at $1.25 \mathrm{~V}(\mathrm{SCE})$ in $4 \mathrm{M} \mathrm{NaCl}$ solution of $\mathrm{pH} 4$ and $80^{\circ} \mathrm{C}$ as a function of time of polarization. Selective dissolution of particular phases from crystalline alloys is clearly observed, whereas the amorphous alloy surface is unchanged.

Fig. 5 shows the high magnification scanning electron micrographs of crystalline $\operatorname{Pd}_{41} \operatorname{Ir}_{40} \mathbf{P}_{19}$ and $\mathrm{Pd}_{50} \mathrm{Ir}_{50}$ alloy surfaces before and after potentiostatic polarization for $1 \mathrm{~h}$ at $1.25 \mathrm{~V}$ (SCE) in $4 \mathrm{M} \mathrm{NaCl}$ of $\mathrm{pH} 4$ and $80^{\circ} \mathrm{C}$. The crystalline $\mathrm{Pd}_{41} \mathrm{Ir}_{40} \mathrm{P}_{18}$ alloy consists of three phases. The phase A dissolves selectively, whereas the other two phases hardly dissolve. On the other hand, the crystalline $\operatorname{Pd}_{50} \mathrm{Ir}_{50}$ alloy consists of two phases. Both phases dissolve and the phase A disappears almost completely after polarization for $1 \mathrm{~h}$. The chemical compositions of respective phases in these crystalline alloys analyzed by X-ray spectroscopy are shown in Table 1 . The chemical compositions are expressed by the ratio of the relative intensity for each element to the sum of relative intensities of respective elements constituting the crystalline alloys. It can be seen that the phase $A$ in the crystalline $\operatorname{Pd}_{41} \operatorname{Ir}_{40} P_{18}$ alloy, which suffers preferential corrosion, is palladium-rich phosphide. The palladium contents of the other two phases are lower than that of the phase A, and as shown in Fig. 5 they are not severely corroded. The crystalline $\mathrm{Pd}_{50} \mathrm{Ir}_{50}$ 


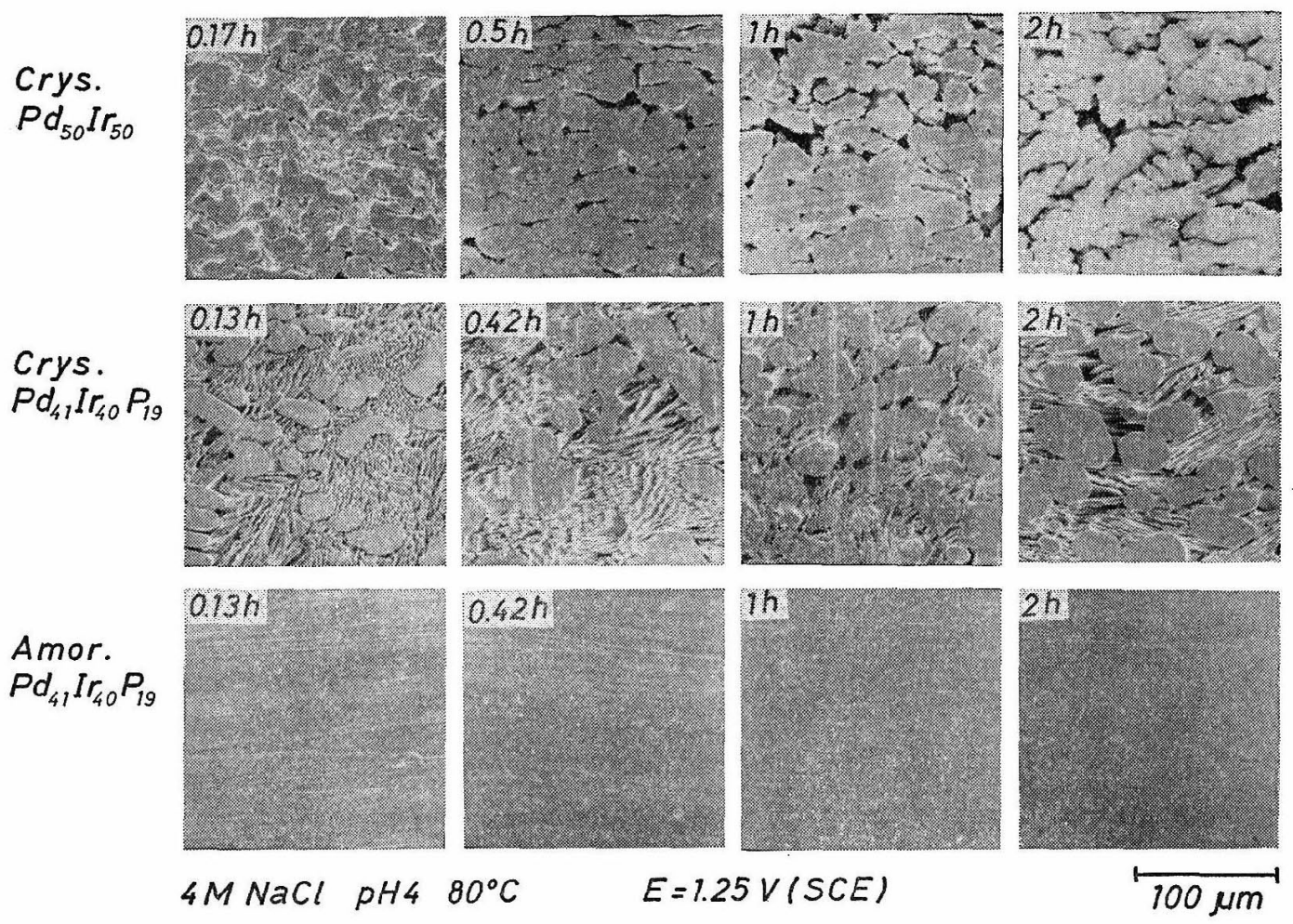

Fig. 4 Changes in surfaces of the amorphous $\mathrm{Pd}_{41} \mathrm{Ir}_{10} \mathrm{P}_{19}$ alloy and crystalline $\mathrm{Pd}_{41} \mathrm{Ir}_{40} \mathrm{P}_{19}$ and $\mathrm{Pd}_{50} \mathrm{Ir}_{50}$ alloys potentiostatic polarization at $1.25 \mathrm{~V}(\mathrm{SCE})$ in $4 \mathrm{M} \mathrm{NaCl}$ of $\mathrm{pH} 4$ and $80^{\circ} \mathrm{C}$.

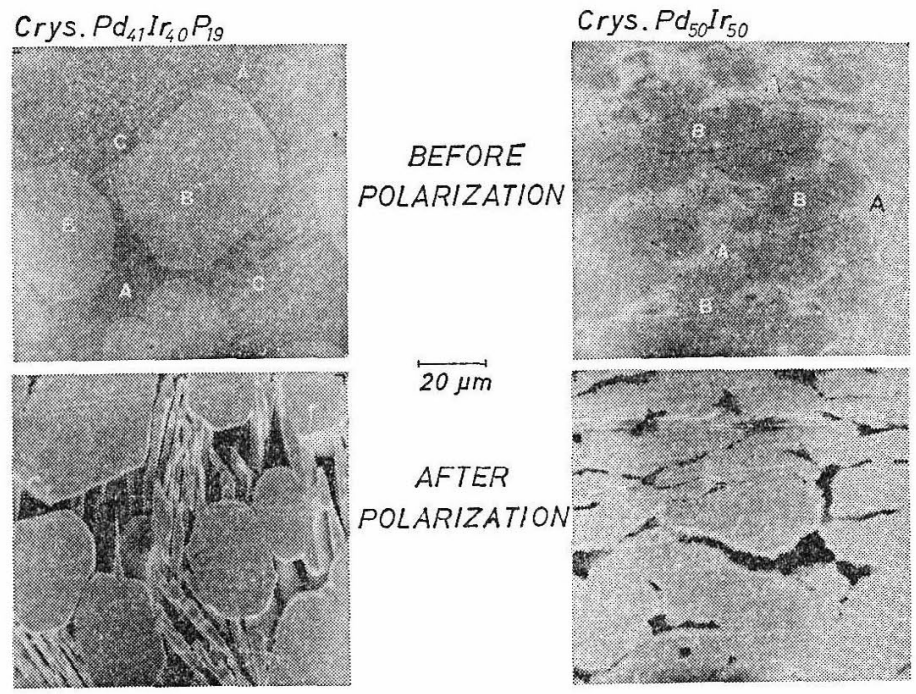

Fig. 5 The surfaces of the crystalline $\mathrm{Pd}_{41} \mathrm{Ir}_{40} \mathrm{P}_{19}$ and $\mathrm{Pd}_{50} \mathrm{Ir}_{50}$ alloys before and after potentiostatic polarization for $1 \mathrm{~h}$ at $1.25 \mathrm{~V}$ (SCE) in $4 \mathrm{M} \mathrm{NaCl}$ of $\mathrm{pH} 4$ and $80^{\circ} \mathrm{C}$. Before polarization: $\mathrm{Pd}_{41} \mathrm{Ir}_{40} \mathrm{P}_{10}$ alloy-Reflection electron image, $\mathrm{Pd}_{50} \mathrm{Ir}_{50}$-Secondary electron image after chemical etching in $100 \mathrm{ml} \mathrm{HCl}$ containing $2 \mathrm{~g}$ of $\mathrm{CrO}_{3}$ for 2 min. After polarization: Secondary electron image. 
Table 1 Chemical compositions of individual phases constituting crystalline $\operatorname{Pd}_{41} \operatorname{Ir}_{40} \mathbf{P}_{19}$ and $\mathrm{Pd}_{50} \mathrm{Ir}_{50}$ alloys. Phases A, B and C are denoted in Fig. 5.

\begin{tabular}{c|c|c|c}
\hline \multicolumn{3}{|c}{ Crystalline $\mathrm{Pd}_{41} \mathrm{Ir}_{40} \mathrm{P}_{19}$} \\
\hline \multirow{3}{*}{ Phase } & \multicolumn{3}{|c}{$I_{\text {specimen }}^{x} / I_{\text {standard }}^{x}$} \\
\cline { 2 - 4 } & $I_{\text {specimen }}^{\mathrm{Pd}} / I_{\text {standard }}^{\mathrm{Pd}}+I_{\text {specimen }}^{\mathrm{Ir}} / I_{\text {standard }}^{\mathrm{Ir}}+I_{\text {specimen }}^{\mathrm{P}} / I_{\text {standard }}^{\mathrm{P}}$ \\
\cline { 2 - 4 } & $\mathrm{Pd}$ & $\mathrm{Ir}$ & $\mathrm{P}$ \\
\hline $\mathrm{A}$ & 0.766 & 0.117 & 0.117 \\
$\mathrm{~B}$ & 0.007 & 0.992 & 0.001 \\
$\mathrm{C}$ & 0.469 & 0.397 & 0.134 \\
\hline
\end{tabular}

\begin{tabular}{c|c|c}
\multicolumn{2}{c}{ Crystalline $\mathrm{Pd}_{50} \mathrm{Ir}_{50}$} \\
\hline \multirow{3}{*}{ Phase } & \multicolumn{2}{|c}{$I_{\text {specimen }}^{x} / I_{\text {standard }}^{x}$} \\
\cline { 2 - 3 } & $I_{\text {specimen }}^{\text {Pd }} / I_{\text {standard }}^{\text {Pd }}+I_{\text {specimen }}^{\mathrm{Ir}} / I_{\text {standard }}^{\mathrm{Ir}}$ \\
\cline { 2 - 3 } & $\mathrm{Pd}$ & $\mathrm{Ir}$ \\
\hline $\mathrm{A}$ & 0.838 & 0.162 \\
$\mathrm{~B}$ & 0.096 & 0.904 \\
\hline
\end{tabular}

alloy consists of palladium-rich and deficient two face-centered cubic phases, and potentiostatic polarization for $1 \mathrm{~h}$ at $1.25 \mathrm{~V}$ (SCE) results in almost complete dissolution of palladium-rich phase A.

Since the corrosion resistance is determined by the nature of the passive film, the composition of the passive films formed on the amorphous and crystalline alloys by polarization at $1.25 \mathrm{~V}$ (SCE) are analyzed by X-ray photoelectron spectroscopy. Table 2 shows the ratio of iridium ions to the sum of metallic cations in the passive films formed on

Table 2 Cationic fractions of iridium in the surface films formed on amorphous $\mathrm{Pd}_{41} \mathrm{Ir}_{40} \mathrm{P}_{18}$ alloy and crystalline $\mathrm{Pd}_{41} \mathrm{Ir}_{40} \mathbf{P}_{19}$ and $\mathrm{Pd}_{50} \mathrm{Ir}_{50}$ alloys by potentiostatic polarization at $1.25 \mathrm{~V}$ (SCE) in $4 \mathrm{M} \mathrm{NaCl}$ of $\mathrm{pH} 4$ and $80^{\circ} \mathrm{C}$.

\begin{tabular}{c|c|c|c|c}
\hline \hline \multirow{2}{*}{ Alloy } & \multicolumn{4}{|c}{$\mathrm{a}_{\mathrm{Ir}} /\left(\mathrm{a}_{\mathrm{Ir}}+\mathrm{a}_{\mathrm{Pd}}\right)$} \\
\cline { 2 - 5 } & Nominal ratio & \multicolumn{3}{|c}{ in Surface Film } \\
\cline { 3 - 5 } & in bulk alloy & \multicolumn{2}{|c}{ After polarization for } \\
\cline { 3 - 5 } & $2 \mathrm{~min}$ & $60 \mathrm{~min}$ & $120 \mathrm{~min}$ \\
\hline $\begin{array}{c}\text { Amorphous } \\
\mathrm{Pd}_{41} \mathrm{Ir}_{40} \mathrm{P}_{19}\end{array}$ & 0.494 & 0.920 & 0.969 & 0.970 \\
$\begin{array}{c}\text { Crystalline } \\
\mathrm{Pd}_{41} \mathrm{Ir}_{40} \mathrm{P}_{19}\end{array}$ & 0.494 & 0.763 & 0.547 & 0.772 \\
$\begin{array}{c}\text { Crystalline } \\
\mathrm{Pd}_{50} \mathrm{Ir}_{50}\end{array}$ & 0.500 & 0.877 & 0.771 & 0.851 \\
\hline
\end{tabular}

the amorphous and crystalline alloys as a function of polarization time. The amorphous alloy is able to form the passive film which consists exclusively of iridium ions as cations.

(b) Palladium-Rhodium Alloys

Fig. 6 shows potentiostatic anotic polarization curves of amorphous and crystalline palladiumrhodium alloys measured in $4 \mathrm{M} \mathrm{NaCl}$ solution of pH 4 and $80^{\circ} \mathrm{C}$. The amorphous $\mathrm{Pd}_{61} \mathrm{Rh}_{20} \mathrm{P}_{10}$ and $\mathrm{Pd}_{51} \mathrm{Rh}_{30} \mathrm{P}_{18}$ alloys are passivated by anodic polarization and show a steep rise in the current density corresponding to chlorine evolution in the potential region higher than about $0.9 \mathrm{~V}$ (SCE). However, the crystalline alloys having the same compositions as amorphous alloys exhibit the higher active dissolution current and are hardly passivated. On the other hand, the crystalline $\mathbf{P d}_{80} \mathrm{Rh}_{20}$ and $\mathbf{P d}_{70} \mathrm{Rh}_{30}$ alloys are passivated by anodic polarization and evolve chlorine gas at high potentials. These Pd-Rh alloys are composed of a single face-centered cubic phase.

Fig. 7 shows a comparison of corrosion rates between amorphous Pd-Rh-P and crystalline Pd$\mathrm{Rh}$ alloys during chlorine evolution by potentiostatic polarization at $1.25 \mathrm{~V}$ (SCE) for $15 \mathrm{~h}$. The corrosion rates of both amorphous and 

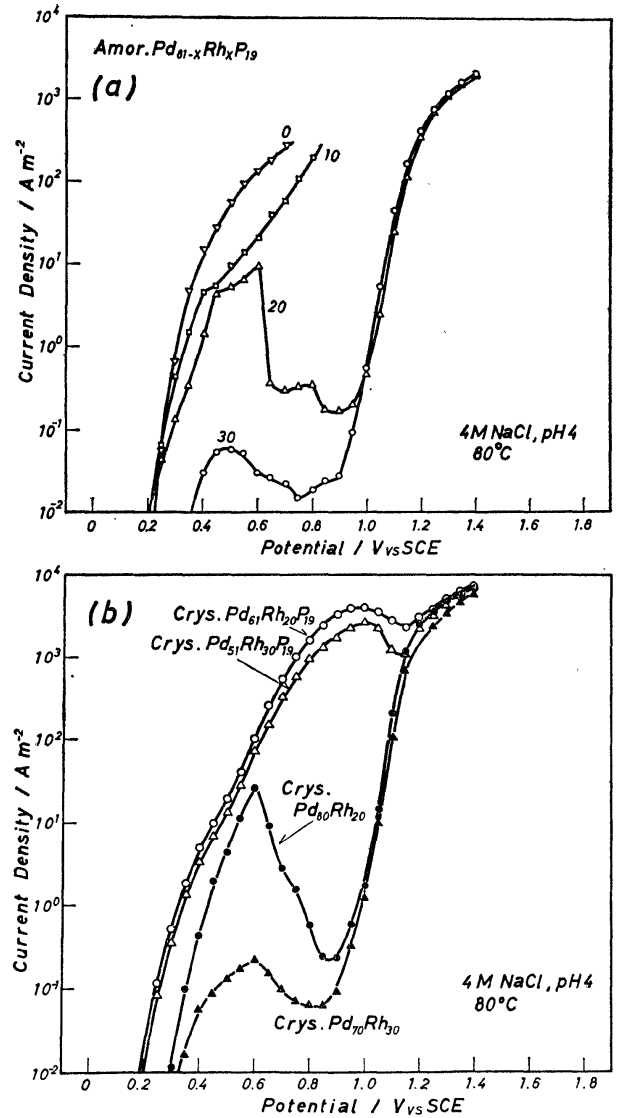

Fig. 6 Potentiostatic anodic polarization curves of (a) amorphous $\mathbf{P d}_{81-x} \mathrm{Rh}_{x} \mathbf{P}_{10}$ alloys and (b) crystalline $\mathbf{P d}_{81-x} \mathrm{Rh}_{x} \mathbf{P}_{19}$ and $\mathbf{P d}_{100-x^{-}}$ $\mathrm{Rh}_{x}$ alloys measured in $4 \mathrm{M} \mathrm{NaCl}$ of $\mathrm{pH} 4$ and $80^{\circ} \mathrm{C}$.

crystalline alloys decrease with increasing rhodium content. The corrosion rate of amorphous Pd$\mathrm{Rh}-\mathrm{P}$ alloy is about two orders of magnitude lower than that of crystalline Pd-Rh alloy of the same rhodium content.

The thicknesses and cationic fractions of rhodium of the passive films formed on the amorphous Pd-Rh-P and crystalline Pd-Rh alloys by potentiostatic polarization at $1.25 \mathrm{~V}$ (SCE) for $1 \mathrm{~h}$ were analyzed by X-ray photoelectron spectroscopy. The results are shown in Fig. 8 as a function of the rhodium content of the alloys. The amorphous alloys are able to accumulate a higher concentration of rhodium ions in the passive films, and hence formation of a thinner film is sufficiently protective.

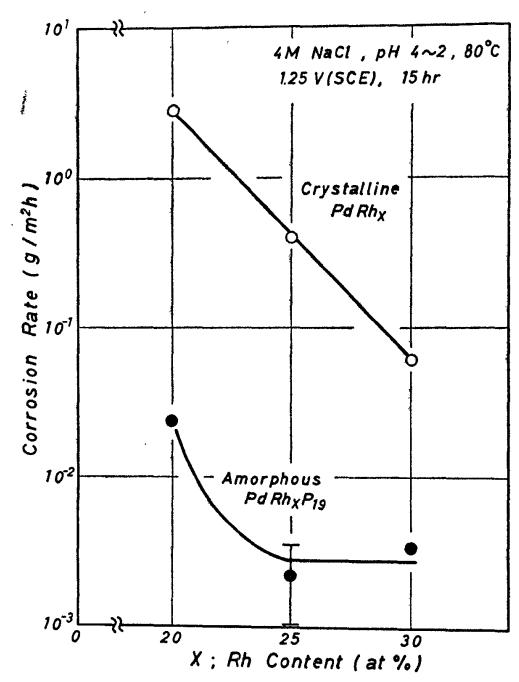

Fig. 7 Average corrosion rates of amorphous $\mathrm{Pd}_{81-x} \mathrm{Rh}_{x} \mathrm{P}_{19}$ and crystalline $\mathrm{Pd}_{100-x} \mathrm{Rh}_{x}$ alloys during potentiostatic polarization for $15 \mathrm{~h}$ at $1.25 \mathrm{~V}$ (SCE) in $4 \mathrm{M} \mathrm{NaCl}$ of $\mathrm{pH} 4$ and $80^{\circ} \mathrm{C}$ as a function of rhodium content.

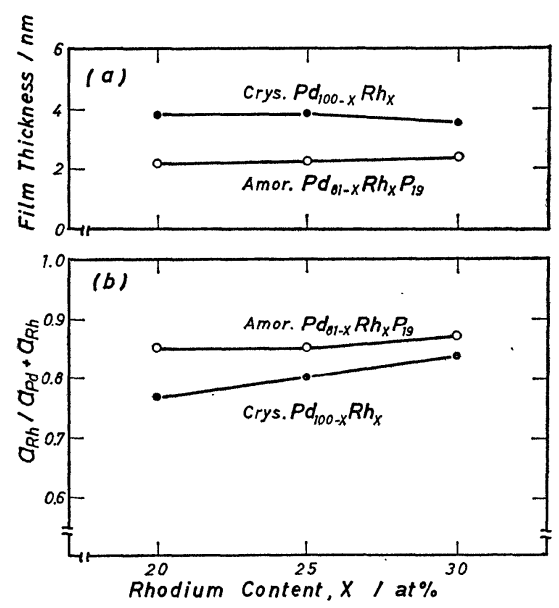

Fig. 8 Thicknesses and cationic fractions of surface films formed on amorphous $\mathrm{Pd}_{81-x} \mathrm{Rh}_{x} \mathrm{P}_{19}$ and crystalline $\mathrm{Pd}_{100-x} \mathrm{Rh}_{x}$ alloys by potentiostatic polarization for $1 \mathrm{~h}$ in $4 \mathrm{M} \mathrm{NaCl}$ of $\mathrm{pH} 4$ and $80^{\circ} \mathrm{C}$ as a function of rhodium content in bulk alloys. (a) Film thickness. (b) Cationic fraction of rhodium in the surface film.

\section{Discussion}

As has been reported previously ${ }^{\text {) }}$, the corrosion resistance of the amorphous palladiumphosphorus alloys under chlorine evolution con- 
ditions in a hot concentrated $\mathrm{NaCl}$ solution is improved by the addition of sufficient amounts of rhodium or iridium. The present work clearly reveals that transformation from the crystalline structure to the amorphous structure is essential to provide the high corrosion resistance for the palladium-phosphorus alloys containing iridium or rhodium. In contrast to the vigorous dissolution of crystalline Pd-Ir-P and Pd-Rh-P alloys under chlorine evolution conditions due to preferential dissolution of palladium-rich phases, the corresponding amorphous alloys evolve chlorine gas without dissolution.

On the other hand, the anodic polarization behavior of the crystalline binary ${ }^{P d_{50}} \mathrm{Ir}_{50}$ alloy is different from that of the crystalline binary Pd-Rh alloys. As shown in Fig. 1, the $\mathrm{Pd}_{50} \mathrm{Ir}_{50}$ alloy exhibits the high current density due to active dissolution and is hardly passivated by anodic polarization. In contrast, the $\mathrm{Pd}-\mathrm{Rh}$ alloys are passivated by anodic polarization and evolve chlorine gas as shown in Fig. 6 (b). Their corrosion rates are also different: The crystalline $\mathrm{Pd}_{50} \mathrm{Ir}_{50}$ alloy suffers severe corrosion during chlorine evolution (Fig. 2), whereas the corrosion rate of the crystalline Pd-Rh alloys is about four orders of magnitude lower than the $\mathrm{Pd}_{50} \mathrm{Ir}_{50}$ alloy (Fig. 7). The crystalline $\mathbf{P d}_{50} \mathrm{Ir}_{50}$ alloy consists of palladium-rich and deficient two face-centered cubic phases in contrast to the Pd-Rh alloys of a single face-centered cubic phase. The high corrosion rate of the crystalline $\operatorname{Pd}_{50} \mathrm{Ir}_{50}$ alloy is attributed to selective dissolution of palladiumrich phase in a similar manner as the crystalline Pd-Ir-P and Pd-Rh-P alloys. It has been known $^{14), 15)}$ that corrosion is enhanced by formation of chemical heterogeneity rather than structural heterogeneity. The corrosion resistance of the crystalline Pd-Rh alloys as well as the amorphous Pd-Ir-P and Pd-Rh-P alloys is attributable to their single phase nature.

A comparison of the amorphous and crystalline single phase alloys reveals that the corrosion rate of the amorphous Pd-Rh-P alloys is about two orders of magnitude lower than that of the crystalline binary Pd-Rh alloys with the same rhodium content (Fig. 7). The crystalline-defect-free amorphous structure is partly responsible for the high corrosion resistance. In addition, an X-ray photoelectron spectroscopic study clearly reveals that the high corrosion resistance of amorphous Pd-Ir-P and Pd-Rh-P alloys during chlorine evolution is provided by formation of passive films in which iridium and rhodium ions are highly concentrated (Table 2 and Fig. 8). The difference in the corrosion resistance between the amorphous Pd-Rh-P and crystalline $\mathrm{Pd}-\mathrm{Rh}$ alloys results partly from the difference in the enrichment of rhodium ions in the films. Similarly, the concentration of iridium ions in the passive film formed on the amorphous $\operatorname{Pd}_{41} \operatorname{Ir}_{40} \mathrm{P}_{18}$ alloy is higher than those on the crystalline $\mathbf{P d}_{41} \operatorname{Ir}_{40} \mathbf{P}_{19}$ and $\mathbf{P d}_{50} \operatorname{Ir}_{50}$ alloys as shown in Table 2, despite the fact that the X-ray photoelectron spectroscopic analysis of the crystalline Pd-Ir-P and Pd-Ir alloys is carried out after the palladium-rich phases are preferentially dissolved from the alloys. Hashimoto et al. ${ }^{15), 16)}$ have revealed that the high corrosion resistance of amorphous chromium-bearing alloys is attributable to the remarkable enrichment of chromium ions into the passive film formed on the alloys, because the high reactivity, that is, the high dissolution rate of the unfilmed amorphous metal-metalloid alloys enhances the enrichment of beneficial chromium ions at the alloy-solution interface.

As can be seen from Fig. 3, the characteristic of the amorphous alloys to form the iridium- or rhodium-enriched passive film also provides the high stability as the anode for chlorine evolution.

\section{Conclusions}

The corrosion behavior of amorphous palladium alloy anodes for chlorine evolution in a hot concentrated $\mathrm{NaCl}$ solution was compared with that of the corresponding crystalline alloys. The following conclusions can be drawn: 
(1) Amorphous palladium alloys have extremely high corrosion resistance as the anode for chlorine evolution.

(2) The high corrosion resistance of amorphous alloys is attributable to the fact that they consist of the homogeneous single phase and are capable of accumulating corrosion-resistant cations in the passive film.

(Rcceived January 27, 1983)

\section{References}

1) M. Takahashi: Soda and Chlorine, 26, 267 (1975).

2) M. Naka, K. Hashimoto and T. Masumoto: Corrosion, 32, 146 (1967).

3) K. Hashimoto, M. Kasaya, K. Asami and T. Masumoto: Boshoku Gijutsu (Corros. Engng.), 26, 445 (1977).

4) M. Naka, K. Hashimoto and T. Masumoto: J. Non-Cryst. Solids, 29, 61 (1978).

5) M. Naka, K. Hashimoto and T. Masumoto: J. Non-Cryst. Solids, 31, 355 (1979).
6) M. Naka, K. Hashimoto and T. Masumoto: J. Non-Cryst. Solids; 34, 257 (1979).

7) M. Hara, K. Hashimoto and T. Masumoto: Electrochim. Acta, 25, 1215 (1980).

8) M. Hara, K. Asami, K. Hashimoto and T. Masumoto: Electrochim. Acta, 25, 1091 (1980).

9) M. Hara, K. Hashimoto and T. Masumoto: J. Appl. Electrochem., 13, 295 (1983).

10) M. Hara, K. Hashimoto and T. Masumoto: Non-Cryst. Solids, 54, 85 (1983).

11) K. Asami and K. Hashimoto: Corros. Sci., 17, 559 (1977).

12) K. Asami, K. Hashimoto and S. Shimodaira: Corros. Sci., 17, 713 (1977).

13) M. Hara, K. Asami, K. Hashimoto and T. Masumoto: Electrochim. Acta, 29, (1983).

14) M. Naka, K. Hashimoto and T. Masumoto: Corrosion, 36, 679 (1980).

15) K. Hashimoto, K. Osada, T. Masumoto and S. Shimodaira: Corros. Sci., 16, 71 (1976).

16) K. Hashimoto, M. Naka, K. Asami and T. Masumoto: Boshoku Gijutsu (Corros. Engng.), 27, 279 (1978). 